\title{
Heterotopic Pregnancy: Challenges in Diagnosis and Management
}

\author{
V. Sunita*, M. Ramya, T. Shruthi, G. Sangeetha \\ Department of Obstetrics and Gynaecology, Sri Devraj Urs Medical College, Kolar, India \\ Email: *venigallasunita@yahoo.co.in
}

Received 21 March 2016; accepted 20 June 2016; published 23 June 2016

Copyright (C) 2016 by authors and Scientific Research Publishing Inc.

This work is licensed under the Creative Commons Attribution International License (CC BY). http://creativecommons.org/licenses/by/4.0/

(c) (i) Open Access

\begin{abstract}
Objectives: 1) To study the obstetric outcome in two women with heterotopic pregnancy, 2) To report the challenges faced during management of these pregnancies. Design: Case study of two heterotopic pregnancies managed by us. Setting: RL Jalappa Hospital and Research Hospital. Patients: Two women with heterotopic pregnancy. Interventions: Laparotomy and management of ectopic component. Main Outcome Measures: Pregnancy outcomes following surgery. Results: Both pregnancies continued with one live birth at 36 weeks and one preterm delivery at 29 weeks with neonatal death subsequently. Conclusion: Pregnancy outcome after surgery for heterotopic pregnancy is guarded and is at high risk for preterm birth. Salpingostomy is a good option when faced with dilemma of whether it is hematosalpinx or ectopic pregnancy instead of salpingectomy.
\end{abstract}

\section{Keywords}

Heterotopic Pregnancy, Hematosalpinx, Ectopic Pregnancy

\section{Introduction}

Heterotopic pregnancy is a rare situation where intrauterine and extra uterine pregnancy occur simultaneously. Incidence in general population is around 1:30,000 for a naturally conceived pregnancy [1]. Two important factors increasing the incidence of heterotopic pregnancy are pelvic inflammatory disease and assisted reproductive technology. Heterotopic pregnancy is a potentially fatal condition and preop diagnosis of heterotopic pregnancy is difficult as the signs and symptoms are not specific. In this paper we are presenting two cases of heterotopic pregnancy presenting with acute abdomen.

${ }^{*}$ Corresponding author.

How to cite this paper: Sunita, V., Ramya, M., Shruthi, T. and Sangeetha, G. (2016) Heterotopic Pregnancy: Challenges in Diagnosis and Management. Open Journal of Obstetrics and Gynecology, 6, 445-450.

http://dx.doi.org/10.4236/ojog.2016.68059 


\section{Case Report}

Case 1: Mrs M aged 20 years G3P1A1L0 was admitted to our institution with history of increasing lower abdominal pain of 10 days duration. Pain had become severe for last one day associated with vomiting and mild bleeding P/V. She was $10^{+5}$ weeks pregnant. This was a spontaneous conception with no history of contraceptive usage. Her first pregnancy was 3 years ago with preterm delivery of $1.5 \mathrm{~kg}$ female baby which died. Second pregnancy was spontaneous abortion at three months of pregnancy.

On examination, patient was conscious and oriented, mild pallor was present. Pulse rate 90/min, BP 120/70 mmHg, Abdominal examination revealed diffuse lower abdominal tenderness. Uterus was just palpable. Bimanual pelvic examination showed cervix os was closed with mild bleeding. There was fullness and tenderness in pouch of Douglas. At this juncture our clinical diagnosis was a threatened abortion probably evolving to inevitable abortion.

Ultrasound revealed a single live intrauterine gestation with CRL corresponding to 10 wks with moderate sub-chorionic haematoma. Left adnexal area showed complex tubo-ovarian mass with increased peripheral vascularity. There was moderate free fluid in the abdomen. The possibility was either a heterotopic pregnancy with left ruptured tubal gestation or ruptured left ovarian hemorrhagic cyst. Her condition rapidly started deteriorating with increasing pallor and fall in blood pressure. She was immediately taken up for laparotomy. On opening the abdomen uterus was gravid and enlarged to 12 weeks size along with left tubal ectopic pregnancy forming a mass of $6 \times 7 \mathrm{~cm}$ (Figure 1). Hemoperitoneum with $500 \mathrm{ml}$ fluid blood and $350 \mathrm{gm}$ clots was present. There was active bleeding from the fimbrial end of tube. Left salpingectomy with suctioning of hemoperitoneum was done. Salpingectomy specimen showed blood clots and products of conception (Figure 2). Care was taken to minimally handle the uterus. Histopathology showed left tubal ectopic pregnancy. Post operatively she received progesterone supplementation. She continued to have vaginal bleeding which gradually reduced over six days. Ultrasound at this stage showed a resolving subchorionic haematoma. She was advised further rest and progesterone supplements. Her pregnancy continued uneventfully and she delivered at $36^{+6}$ weeks gestation a live female baby weight $2.3 \mathrm{kgs}$. The child was born with bilateral congenital talipes equano-varus.

Case 2: Mrs A aged 23 yrs was a primigravida with $8^{+1}$ weeks gestation. She was admitted with complaints of

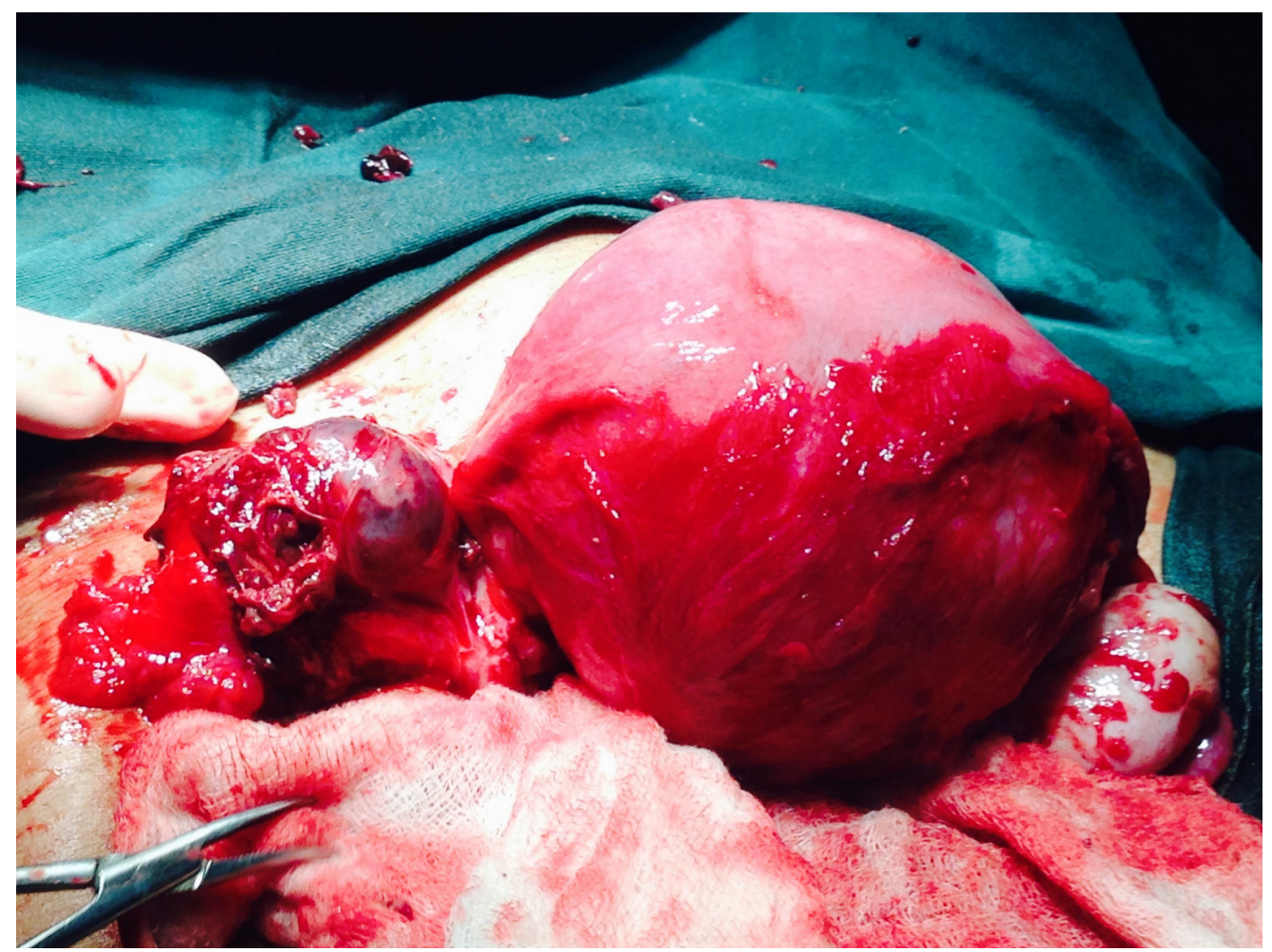

Figure 1. Gravid uterus with tubal ectopic. 


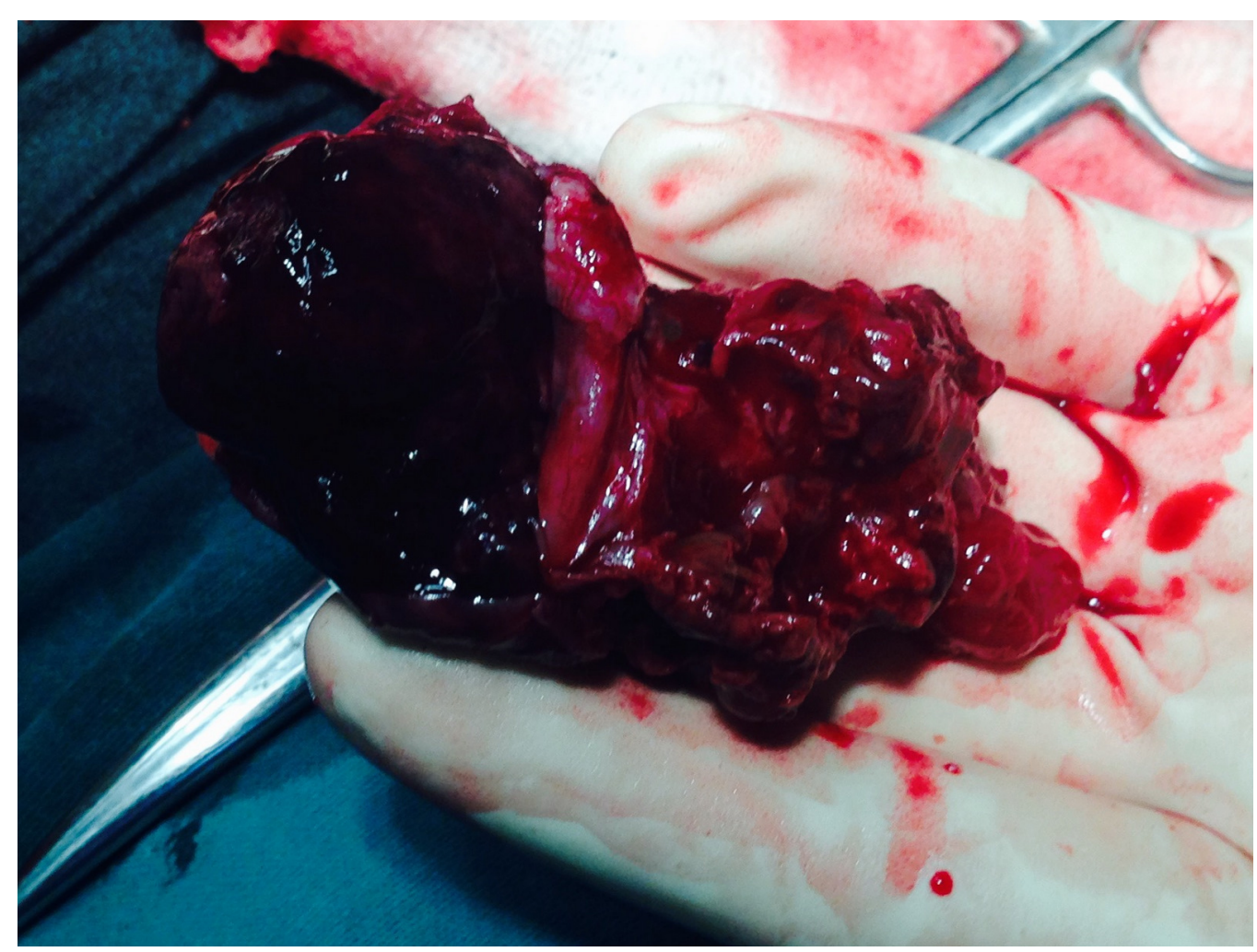

Figure 2. Salpingectomy specimen.

severe lower abdominal pain abdomen of 15 days duration, vomiting for 1 week and generalised weakness. She was married for 2 years and had taken treatment for infertility outside with clomiphene citrate. She had undergone apppendicetomy 1 year back.

On examination she was conscious, oriented. Pallor was present. Per abdomen there was lower abdominal distension, guarding and diffuse tenderness. Bimanual pelvic examination revealed uterus was enlarged to eight weeks size. Cervical movements were tender and both fornices were tender and full. Ultrasound showed a single live intrauterine gestation with left adnexal mass (Figure 3). Intrauterine gestation had crown rump length corresponding to 8 weeks with thin sub-chorionic collection. There was left tubo-ovarian complex mass surrounded by free fluid containing echogenic debris suggestive of hemoperitoneum and moderate free fluid in the abdomen. Impression was ruptured ovarian cyst or heterotopic pregnancy with ruptured tubal gestation.

In view of deteriorating clinical condition, she was taken up for exploratory laparotomy. Intra-operatively there was hemoperitoneum of $300 \mathrm{ml}$ along with $150 \mathrm{gm}$ clots. Uterus was enlarged to 8 - 10 weeks size with right tubal pregnancy near the fimbrial end with active bleeding. Left tube was irregularly distended with blood with active bleeding (Figure 4). This intra operative picture resembled a tubal abortion on left side. We were faced with probable bilateral ectopic pregnancy in a primigravida. Bilateral salpingectomy could not be done as loss of intrauterine pregnancy would leave her with no option except in vitro fertilization and embryo transfer. In view of this situation we opted for bilateral salpingostomy. On the right side tube was opened at the site of ectopic which was very close to fimbrial end and products were evacuated and haemostasis secured. On left side the tube was opened at the site of maximum distension and few clots were removed and tube was irrigated with saline. Tissue from both the fallopian tubes was sent for histopathology. Hemoperitoneum was suctioned out taking care in minimal handling of uterus. Histopathology of right tubal mass showed chorionic villi, sheets of trophoblast, memebranes and few syncitiotrophoblast admist extensive areas of hemorrhage. Left sided tubal mass showed extensive areas of hemorrhage and fibrinoid necrotic material and no evidence of products of conception.

Postoperatively patient received progesterone supplementation and one unit of blood transfusion. She had uneventful postoperative period. She subsequently had a live preterm delivery of female baby weight $1.1 \mathrm{~kg}$ at 


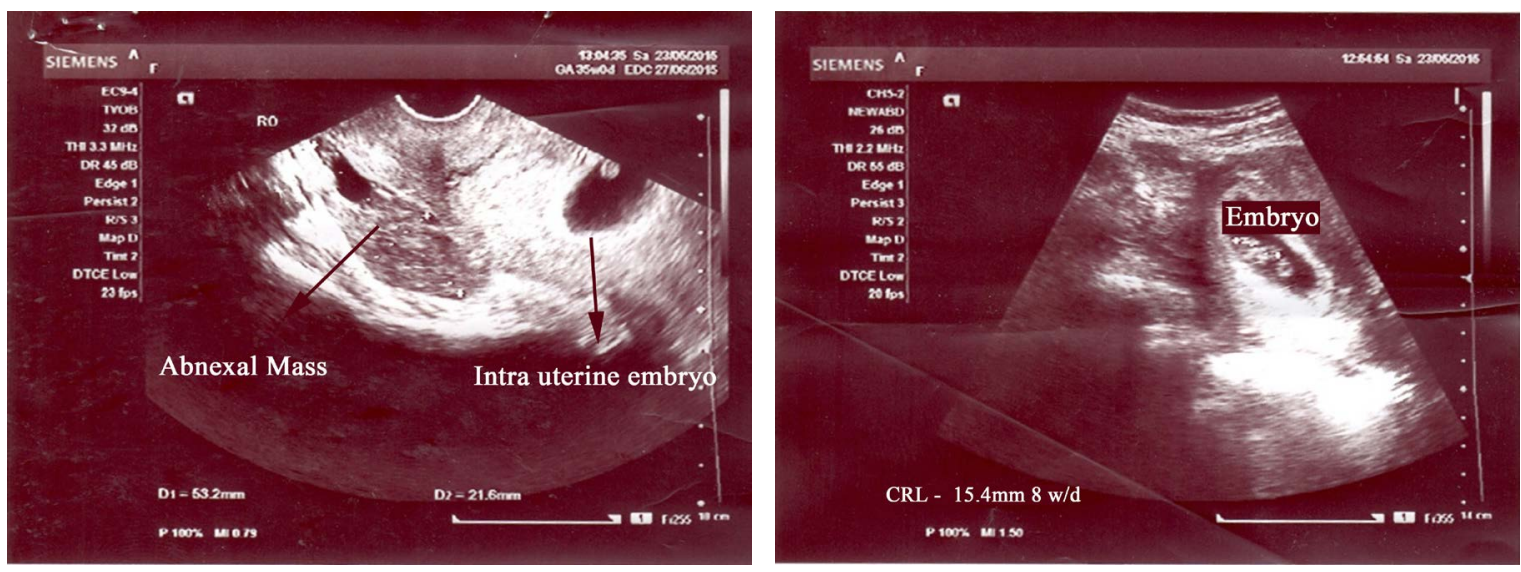

Figure 3. Ultrasound picture of intrauterine pregnancy with adnexal mass.

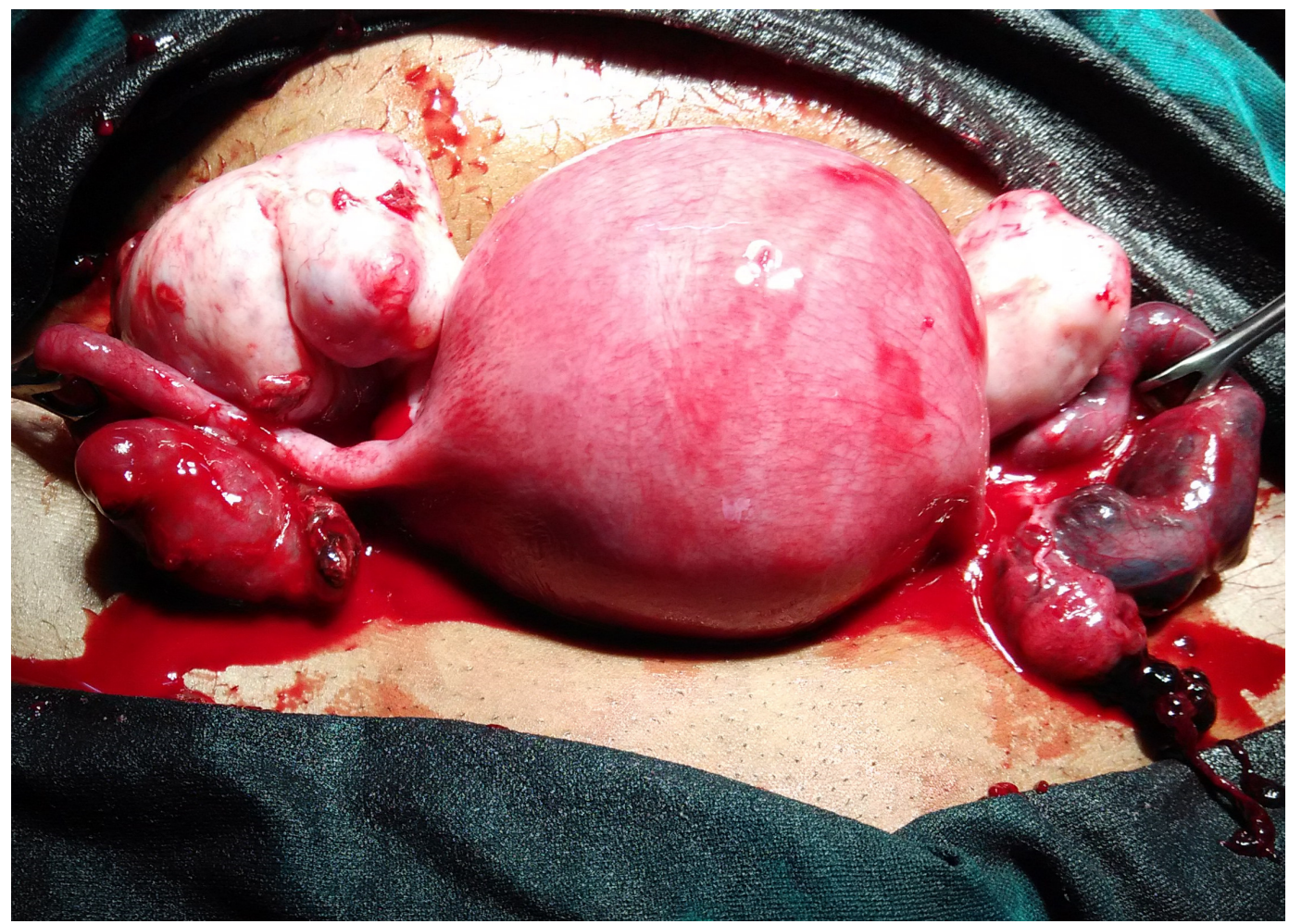

Figure 4. Gravid uterus with right tubal ectopic and left tube distended with blood with active bleeding.

$29^{+2}$ weeks gestation. Baby was admitted in NICU but expired after two weeks.

\section{Discussion}

Heterotopic pregnancy is a rare condition and incidence in general population is around 1:30,000 for a naturally conceived pregnancy [1].

Majority of heterotopic pregnancies reported in the literature are following ART procedures [2]. Some cases of heterotopic pregnancy are also reported after ovulation induction with gonadotrophins or with clomiphene citrate [3]. Rarely some may be spontaneous conception with risk factors like previous history of ectopic pregnancy or sometimes even without risk factors [2] [4]. Our case 1 was also a spontaneous conception without any risk factors and second case had ovulation induction with clomiphene citrate.

Preoperative diagnosis of heterotopic pregnancy poses several dilemmas as beta-HCG is not helpful in diag- 
nosis. In the absence of live ectopic gestation, presence of adnexal mass may be confused with luteal cyst or corpus-luteal cyst haemorrhage if there is free fluid in the abdomen. A right sided heterotopic tubal ectopic can also mimic pregnancy with appendicitis. Women with heterotopic pregnancy following ovulation induction with gonadotrophins may also have ovarian hyper stimulation syndrome with associated ascites and multiple ovarian follicles which compounds the diagnostic dilemma [2]. Aspiration of fluid in such cases can distinguish blood from ascitic fluid. Ultrasound features of echogenic fluid in pouch of douglas suggest presence of hemoperitoneum. Earlier published reviews suggest that ultrasound is diagnostic of heterotopic pregnancy only in $41.07 \%$ of women [2].

In our case 1 we considered haemorrhage from corpus luteum as most probable diagnosis after reviewing the ultrasound findings as it was a spontaneous conception without any risk factors. Heterotopic pregnancy was a intraoperative diagnosis. Both our patients were admitted with one week interval which is a rare occurrence.

Management of heterotopic pregnancy is to preserve viable intrauterine gestation and either medical or surgical management of ectopic component. Medical management with systemic methotrexate however is not a feasible option as it may affect the intrauterine gestation. Local injection of methotrexate after aspiration of cornual/interstitial gestational sac in heterotopic pregnancy has been reported [5]. Some authors have managed heterotopic pregnancy medically by injecting potassium chloride into ectopic sac [6].

Surgical management of ectopic component may be radical (salpingectomy) or conservative (salpingostomy) either by laparoscopy or laparotomy. The most important surgical principal to be kept in mind is minimal handling of the uterus.

Our second patient (case 2) presented dilemma in management as one tube was clearly ectopic gestation with bleeding from fimbrial end. The opposite tube was irregularly distended with bleeding from the fimbrial end giving rise to suspicion of tubal abortion. Salpingectomy was not an option as she desired future fertility. We performed bilateral salpingostomy and irrigated the tubes with saline leaving them patent. Histopathology of right tubal mass showed chorionic villi, sheets of trophoblast, membranes and few syncitiotrophoblast. Left sided tubal mass showed extensive areas of hemorrhage and fibrinoid necrotic material. We therefore hypothesised that the false impression of ectopic was a result of reflux of blood from the tubal abortion in opposite tube. We have not come across such a picture in any of the literature reviews of heterotopic pregnancy. Bilateral tubal ectopics are reported in literature following in vitro-fertilisation and have been treated either with laparotomy and bilateral salpingectomy or laparoscopic linear salpingostomy on one side and salpingectomy on the other side [7] [8].

\section{Conclusion}

Heterotopic pregnancy can occur in the absence of any risk factors. Heterotopic pregnancy should be a differential diagnosis in pain abdomen with pregnancy. In the presence of bilateral tubal ectopic, salpingostomy rather than bilateral salpingectomy is preferable in order to preserve future fertility.

\section{Acknowledgements}

We thank Dr GK Narayana for assistance in preparation of manuscript and photos for the paper.

\section{References}

[1] Richards, S.R., Stempel, L.E. and Carlton, B.D. (1982) Heterotopic Pregnancy: Reappraisal of Incidence. American Journal of Obstetrics \& Gynecology, 142, 928-930.

[2] Barrenetxea, G., Barinaga, R.L., Lopez de Larruzea, A., Agirregoikoa, J.A., Mandiola, M. and Carbonero, K. (2007) Heterotopic Pregnancy: Two Cases and a Comparative Review. Fertility Sterility, 87, 417e9-417e13. http://dx.doi.org/10.1016/j.fertnstert.2006.05.085

[3] Ghandi, S., Ahadi, R. and Fazel, M. (2011) Heterotopic Pregnancy Following Induction of Ovulation with Clomiphene Citrate. Iranian Journal of Reproductive Medicine, 9, 319-321.

[4] Basile, F., Cesare, D.C., Quagliozzi, L., Donati, L., Bracaglia, M., Caruso, A. and Paradisi, G. (2012) Spontaneous Heterotopic Pregnancy Simultaneous Ovarian and Intrauterine: A Case Report. Case Reports in Obstetrics and Gynecology, Article ID 509694, 4 p.

[5] Oyawoyea, S., Chander, B. and Pavlovic, B. (2003) Heterotopic Pregnancy: Successful Management with Aspiration of Cornual/Insterstitial Gestational Sac and Installlation of Small Dose of Methotrexate. Fetal Diagnosis and Therapy, 
18, 1-4. http://dx.doi.org/10.1159/000066374

[6] Fernandez, H., Lelaidier, C., Doumerc, S., Fournet, P., Olivennes, F. and Frydman, R. (1993) Non Surgical Treatment of Heterotopic Pregnancy: A Report of Six Cases. Fertility Sterility, 60, 428-432. http://dx.doi.org/10.1016/S0015-0282(16)56155-X

[7] Pan, H.-S., Chuang, J., Chiu, S.-F., Hsieh, B.-C., Lin, Y.-H., Tsai, Y.-L., Huang, S.-C., et al. (2002) Heterotopic Triplet Pregnancy: Report of a Case with Bilateral Tubal Pregnancy and an Intrauterine Pregnancy. Human Reproduction, 171, 1363-1366. http://dx.doi.org/10.1093/humrep/17.5.1363

[8] Klipstein, S. and Oskowitz, S.P. (2000) Bilateral Ectopic Pregnancy after Transfer of Two Embryos. Fertility and Sterility, 74, 887-888. http://dx.doi.org/10.1016/S0015-0282(00)01566-1

\section{Submit or recommend next manuscript to SCIRP and we will provide best service for you:}

Accepting pre-submission inquiries through Email, Facebook, Linkedin, Twitter, etc A wide selection of journals (inclusive of 9 subjects, more than 200 journals)

Providing a 24-hour high-quality service

User-friendly online submission system

Fair and swift peer-review system

Efficient typesetting and proofreading procedure

Display of the result of downloads and visits, as well as the number of cited articles

Maximum dissemination of your research work

Submit your manuscript at: http://papersubmission.scirp.org/ 